\title{
The Capability and Support of Structure Capital on BIM Innovation in SME
}

\author{
Sa'id Kori, $\mathrm{PhD}^{1 *}$ Moses Itanola ${ }^{2}$ Abdullahi B. Saka ${ }^{3}$ \\ 1. Department of Architecture, University of Liverpool, Liverpool, UK. \\ 2. Research and Development, BIM Africa Initiative, Nigeria. \\ 3. Department of Building and Real Estate, The Hong Kong Polytechnic University, Hong Kong.
}

\begin{abstract}
The Architecture, Engineering, and Construction (AEC) industry has been changing over the years with the emergence of BIM. The small and medium sized enterprises are not left out of the change, bringing distortion to their business environment and process. Extant studies have revealed that Structure Capital (SC) is an integral part of the innovative capacity of firms, this study examines the capability of SC on Architectural SME firms in Nigeria. The research was designed in three stages, empirical enquiry, analysis, and synthesis. The empirical enquiry comprised of theory formulation and fieldwork data collection. The theory formulation was achieved by proposing an evaluation framework using a systematic literature review on three SC components; system structure, infrastructure and facilities, and process and scheme. The evaluation framework constituted a set of independent variables comprising thirteen indicators categorised under these three components. The evaluation framework was used to collect data from the fieldwork. It involved a questionnaire survey and case study interviews with a sample of SME architectural firms in Nigeria. The survey involved administering questionnaires to 334 firms which yielded 217 completed questionnaires. Six case study interviews were also conducted within the same period. The survey data enabled the evaluation of the framework using a multiple regression analysis. To examine the relationship between these components and the BIM Business Value Capital (BBVC), a multiple linear regression and correlation analysis was conducted to assess whether the independent variables predict the dependent variable. The result indicated that all the three components of the SC have a significant correlation with BBVC. However, some indicators were not found to be useful in predicting BBVC, which include: flexible administrative systems and knowledge management system structures. In comparison, the availability of specific office infrastructures for BIM and the availability of in-house training were found to be useful. The research concluded that the development of the SC of SME firms in the AEC industry is essential for the business process of BIM adoption.
\end{abstract}

Keywords: BIM, Structure Capital (SC), SME, Architect, BBVC.

DOI: $10.7176 / \mathrm{IKM} / 9-2-06$

\section{Introduction}

Building on the definition by (Lu and Sexton 2009), Structure Capital (SC) is described as the built-in capital of organisational systems, processes, and schemes, tools, rules and routines. SC can, therefore, be defined as everything that is owned by the firm that is not the Human Capital (HC) or Relationship Capital (RC) but serving the purpose of both when the routine of work is active. It is primarily explicit and rule-based and can exist independent of the human resources of the firm. (Aramburu, Sáenz and Blanco 2013) described it as the capital demonstrating all of the value that is left behind in the organisation when the employees have left the workplace. (Karchegani, Sofian and Amin 2013) suggested it could include codified knowledge, procedures, processes, goodwill, patents, and culture. SC is also described as the organisational competencies of the firm comprising the routines, procedures, processes, systems, culture, databases, structures and intellectual property. They further argued that it is an intangible asset that is formed to allow the $\mathrm{HC}$ and the $\mathrm{RC}$ to develop. However, due to the explicit organisational nature of its function, $\mathrm{SC}$ has been called numerous names. For example, due to its process-centred function, (Namvar et al. 2012) called it process capital. They suggest that it is formed as a result of investments, processes, structures, and activities established by organisations and aimed at changing or maintaining HC or influencing RC. Meanwhile, (Egbu 2004) called it organisational capital since it represents the knowledge in processes, systems, and structures, as well as behaviours, norms, mental maps, core competencies, and culture, and thus influence outputs in the organisation. (Chen, Zhu and Yuan Xie 2004) called it innovation capital because of its explicit service as a powerhouse to intellectual property, such as patents, copyrights, and trademarks as well as other intangible assets, such as the talents and theory by which an organisation is run. (Karchegani et al. 2013) suggested that an effective SC is that which provides a supportive environment for effective knowledge sharing, collective knowledge development, and more productive human resources. (Ngah and Ibrahim 2011) suggested that, as a system for coding, storing, transmitting and sharing knowledge, SC can be described as the knowledge embedded in the non-human storehouses and routines of the organisation. In addition, ( $\mathrm{Lu}$ and Sexton 2009) stated that it consists of the organisation's mechanisms and structures, such as patents, concepts, models, computers and administrative systems as well as organisational 
culture, and these can help support employees in a quest for optimum performance

(Edvinsson and Malone 1997) highlighted the importance of SC in innovation suggesting it is an integral part of the innovative capacity of firms. Furthermore, the importance of SC as an integral part of the BIM adoption process is emphasised by numerous studies (Succar and Kassem 2015, Newton, Hampson and Drogemuller 2009, Codinhoto et al. 2013). Given this context, some of the common themes arising in these definitions include processes, systems, structures, routines, procedures, culture, databases, intellectual property, schemes, tools, rules and patents, concepts, models, computer, administrative systems, supportive environment, copyrights, and trademarks. Although most of these terms are similar in meaning and importance, they are not all relevant to the BIM adoption process or to the context of the study. Therefore, the study adopts some of the major classifications of this item from the literature (Lu and Sexton 2009, Succar 2009, Egbu 2004) and, where relevant, some of the items are used as indicators for the major classes (Aramburu et al. 2013). Consequently, three classes were identified and form the components of the Structure Capital for this study; these are;

- $\quad$ The capability and support of the firm's systems and routines

- $\quad$ The capability and support of the firm's infrastructure and facilities

- $\quad$ The capability and support of the firm's process and schemes.

\subsection{THE CAPABILITY AND SUPPORT BY FIRM SYSTEM STRUCTURE}

The importance of the capability and support of a firm's system and structure in fostering innovation has been well documented in the literature (Aramburu et al. 2013, Lu and Sexton 2009, Damanpour and Gopalakrishnan 2001), and explicitly recorded in the realisation of BIM Business Value Creation - BBVC (Vass 2015). This component refers to the type of administrative systems in place within a firm, the specific units of a firm and work teams that make up this system, the communication channels (both vertical and horizontal) that link the aforementioned units and teams, and the physical design of the workplace (Aramburu et al. 2013). (Aramburu et al. 2013) suggested four elements with regard to the organisation capital, which provide a basis for developing a viable indicator that could define this component. These are; administrative systems, knowledge management system, policies and guidelines, and culture and strategies. In the same study, they also argued that the type of administrative system and the effectiveness of communication channels are critical to innovation capability. Given the context of this study and considering the holistic coverage of the three components of structure capital, it is necessary to identify and avoid the overlapping of some indicators. Hence, this study identified four indicators in the capability and support of a firm's systems and routines when predicting the business value of BIM. These are discussed below.

( $\mathrm{Lu}$ and Sexton 2009) explicitly suggested that the administrative system is a critical variable that defines successful innovation in SME architectural firms in the construction industry. (Aramburu et al. 2013) highlighted that certain types of administrative system facilitate knowledge sharing and knowledge creation processes more than others and are more learning-supportive. In particular, (Nonaka and Toyama 2003) suggested that a system of flexible and informal organisation and management that is combined with a hierarchy structure conducive for the fostering of knowledge creation is better than rigid bureaucracy.

Furthermore, (Aramburu et al. 2013) stated that an effective communication channel can play a significant role in developing effective knowledge sharing and subsequent knowledge creation. (Kalla 2005) described an effective knowledge management system as the function of integrated internal communications. This is particularly true in the case of a BIM process, which mainly relies on value creation through effective communication and collaboration (Arayici et al. 2011). (Aramburu et al. 2013) argued that, although traditional knowledge flows were largely vertical, from the top management to the employees, supervisor to workers, in order to ensure effective knowledge management systems, firms need to also encourage horizontal knowledge flow to create innovation in their business value. Hence, an effective knowledge sharing system can be regarded as a catalyst for a competitive advantage. Thus, (Aramburu et al. 2013) explicitly suggested that administrative systems and knowledge management systems play a critical role in the innovation capability of firms.

With regard to flexible policy systems for innovation, (Succar 2009) explicitly highlighted the positive impact of clear and supportive policies and guidelines in enabling a smooth BIM adoption process. For example, (Aramburu et al. 2013) suggested that some firms deploy and adopt innovative professional policies and record positive impacts on their innovation capabilities.

In terms of allowing an experimentation culture, (Aramburu et al. 2013) suggested that the link between innovation, supportive cultures and knowledge sharing is critical, and argued that an experimentation culture allows for the continuous questioning of established patterns and for new idea generation and testing. (Friedman, Lipshitz and Overmeer 2001) suggested that the implementation of a system that accommodates experimentation culture can lead to an improvement in a firm's cultural values for innovation, such as increased trust and transparency, open mentality, mistakes considered as learning opportunities, support for experimentation and the exploration of new territories, and cooperation and mutual help.

Considering the above discussion within the context of this study, the following hypotheses are formulated 
which is also illustrated in Figure 1.

H80: The capability and support of SME architectural firms through system structure have a significant correlation with BBVC.

H81: The capability and support of SME architectural firms through system structure have no significant correlation with BBVC.

Sub-Hypotheses:

- H8a: Firms that develop their capability and support through flexible administrative system for innovation are likely to succeed in BBVC.

- $\quad$ H8b: Firms that develop their capability and support through effective knowledge management systems are likely to succeed in BBVC.

- H8c: Firms that develop their capability and support through flexible policy systems for innovation are likely to succeed in BBVC.

- $\quad$ H8d: Firms that develop their capability and support through systems for experimentation culture are likely to succeed in BBVC

\subsection{THE CAPABILITY AND SUPPORT BY FIRM INFRASTRUCTURE}

The relationship between the capability and support of an SME architectural firm's infrastructure and their facility and successful innovation within the construction industry is explicitly highlighted by (Lu and Sexton 2009) and particularly linked with the BIM adoption process (Succar 2009). (Aramburu et al. 2013) suggested that the efficacy of this component in enhancing innovation and knowledge sharing is particularly popular amongst information system studies. (Aramburu et al. 2013) also suggested that the availability of specific technological tools that foster the capture and storing of knowledge, as well as the connection between individuals, are relevant aspects of this component when considering the innovation capacity of firms. (Succar 2009) stated that numerous indicators of this component form a requirement for BIM maturity in firms, and these are; software facilities, hardware facilities, network facilities, work environmental infrastructure, and upgrade and maintenance facilities. (Aramburu et al. 2013) highlighted the importance of this component for the improvement of knowledge sharing and innovation capabilities within a firm suggesting that the most important factor shaping the quality of knowledge lies in the quality of the workplace that supports innovation. Given these definitions, the study adopts all five indicators mentioned, which are the availability of; software facilities, hardware facilities, network facilities, maintenance, and upgrade facilities, and a conducive working environment.

(Succar 2009) describes software facilities as the ability of the firm to avail itself with all the required applications, deliverables, and data. Similarly, in the case of hardware facilities, it involves equipment, computers, and deliverables. Network facilities involve networking solution deliverables, security/access control systems, and internet and intranet facilities that the firm uses to improve its knowledge resources and create competitive advantage. (Aramburu et al. 2013) described the availability of a conducive work environment as the intangible area for knowledge management and emphasised that its availability and quality in a firm can enhance the innovation process. However, (Succar 2009) simply referred to such infrastructure as any physical environment that supports knowledge-related sharing activities. (Succar 2009) described the ongoing maintenance and upgrade of all infrastructural facilities as a suitable way to reap the BBVC in a firm. Building from the literature of exploitative innovation, (Lichtenthaler and Lichtenthaler 2009, Lu and Sexton 2009) explicitly highlighted the importance of sustaining the components of structure capital over a period.

Given the above discussion, the study formulates the following hypotheses which are also illustrated in Figure 1;

H90: The capability and support of SME architectural firms' organisational infrastructure and facilities have a significant correlation with BBVC success.

H91: The capability and support of SME architectural firms' organisational infrastructure and facilities have no significant correlation with BBVC success.

Sub-Hypotheses:

- H6a: Firms that develop their capability and support through the availability of hardware facilities are likely to succeed in BBVC.

- H6a: Firms that develop their capability and support through the availability of software facilities are likely to succeed in BBVC.

- H6a: Firms that develop their capability and support through the availability of network facilities are likely to succeed in BBVC.

- H6a: Firms that develop their capability and support through the availability of specific office space for ICT units are likely to succeed in BBVC.

- H6a: Firms that develop their capability and support through the availability of maintenance and 
upgrade facilities for technology are likely to succeed in BBVC.

\subsection{THE CAPABILITY AND SUPPORT BY FIRM PROCESS}

( $\mathrm{Lu}$ and Sexton 2009) highlighted the importance of a reward and incentive scheme as an effective means of promoting ideas' generation among employees and increasing the innovative capability of firms. (Succar 2009) suggested that training can also play a significant role in the preparatory stages of a firm's BIM adoption process. ( $\mathrm{Lu}$ and Sexton 2009) emphasised the internal training scheme as the most effective means to leverage both HC and $\mathrm{RC}$, using the support of the SC.

With regard to strategic innovation management schemes, (Ichijo 2007) described these as a series of guideline principles that a firm can adopt in order to indicate to an organisation's members which areas of knowledge creation or innovation should be pursued. (Aramburu et al. 2013) highlighted that firms who have such strategic management schemes are able to facilitate their innovation capabilities and have a better competitive advantage in creating business value. (Dorrego, Costa and Fernández 2013) suggested that firms who clearly established such schemes and shared innovation strategies recorded an increased effectiveness in their process for generating new ideas process, and their innovation project management. This is also true in the BIM process; (Succar 2009) confirmed that firms with a BIM implementation strategy reap the benefits of BBVC, which can help them sustain their knowledge resource through a long-term competitive advantage.

Moreover, (Aramburu et al. 2013) suggested that, among the characteristics of firms that establish this type of system and record a substantive competitive advantage in their innovativeness, a specific organisational unit, or group of qualified people, exist devoted to facilitating the generation and implementation of new ideas. The existence of such a unit gives a formal impulse to the generation of a specific cycle for innovation. (Nonaka and Takeuchi 1996) described this cycle for innovation as a physical or virtual space where knowledge sharing and knowledge creation takes place.

Placing the above discussion within the context of this study, the following hypotheses were formulated which is also illustrated in Figure 1;

H100: The capability and support of organisational process and schemes of SME architectural firms have a significant correlation with BBVC.

H101: The capability and support of organisational process and schemes of SME architectural firms have no significant correlation with BBVC.

Sub-Hypothesis;

- H6a: Firms that develop their capability and support through reward and incentive schemes for innovation are likely to succeed in BBVC.

- H6a: Firms that develop their capability and support through in-house training schemes for innovation are likely to succeed in BBVC.

- H6a: Firms that develop their capability and support through strategic innovation management schemes are likely to succeed in BBVC.

- H6a: Firms that develop their capability and support through research and development schemes are likely to succeed in BBVC.

\subsection{MEASURE OF BIM SUCCESS IN THE SME ARCHITECTURAL FIRMS.}

This section discusses the dependent variable of the study, which is BBVC. It starts by defining BIM from the business perspective, and the emergence of the term 'business value' in BIM. Subsequently, the study defines the term BBVC through the literature of IT business value and built its case from that field. (Vass 2015) suggested that most studies on measuring business value in the field focus on evaluating the value of IT. Others concentrate on determining suitable metrics or key performance indicators to measure and evaluate the effects of implementing IT, and in particular to measure any increased productivity from IT. This is also true in the case of current construction management and BIM research (Vass 2014, Construction 2014, Aranda-Mena et al. 2009, Barlish and Sullivan 2012). For example, (Curley 2004) explicitly states that, in order to measure the business value of IT in a firm, a maturity and capability metric is essential. This is also reiterated by (Succar 2009) and (Aranda-Mena et al. 2009) who argued that generating business value through BIM is highly dependent on the individual capabilities of firms. Similarly, (McGraw-Hill 2009) suggested that numerous successful firms invest to make sure clients are aware of their BIM capabilities in order to create business value. All the above assertions point to the level of maturity and capability as essential in generating IT business value. (Curley 2004, Racheva, Daneva and Sikkel 2009, Kohli and Grover 2008).

\section{Methodology}

The study was designed in three stages, empirical enquiry, analysis, and synthesis. The empirical enquiry comprised of theory formulation and fieldwork data collection. The theory formulation was achieved by proposing an evaluation framework using a systematic literature review on the three SC components. The 
evaluation framework constituted a set of independent variables comprising thirteen indicators categorised under the three components. Each component was defined by a set of indicators, and the proposition suggested a relationship between these indicators, the components of the $\mathrm{SC}$, and a dependent variable of the BBVC.

The evaluation framework was used to collect data from the fieldwork. It involved a questionnaire survey and case study interviews with a sample of SME architectural firms in Nigeria. The survey involved administering questionnaires to 334 firms which yielded 217 completed questionnaires. Six case study interviews were also conducted within the same period. The survey data enabled the evaluation of the framework using a multiple regression analysis. Each component and its sets of indicators represented an independent model of regression in the analysis. The outcome provided statistical evidence of the relationship between the two main variables. Also, it provided the Relative Weighting Value (RWV) for each of the indicators on the components and their effects on the BBVC.

In this study, the independent variables included the forty-nine indicators of the theoretical model categorised under thirteen components. While each component with its indicators served as an independent regression model throughout the analysis, the dependent variable remained the BBVC. To examine the relationship between these components and the BBVC, a multiple linear regression and correlation analysis was conducted to assess whether the independent variables predict the dependent variable (criterion). A multiple linear regression assesses the relationship between a set of dichotomous, or ordinal, or interval/ratio predictor variables on an interval/ratio criterion variable (Solutions 2013). Hence, the following regression equation (main effects model) was used for each component as a regression model:

$\mathrm{y}=\mathrm{b} 0+\mathrm{b} 1 \mathrm{x} 1+\mathrm{b} 2 \mathrm{x} 2+\ldots \ldots .+\mathrm{bnxn}+\mathrm{e}$

Where, $\mathrm{y}=$ estimated dependent variable $(\mathrm{BBVC})$

$\mathrm{e}=$ constant (which includes the error term),

$\mathrm{b}=$ regression coefficients and

$\mathrm{x}=$ each independent variable (the individual indicators (predictors) of the component)

$\mathrm{n}=$ number of indicators under a component.

A standard multiple linear regression, called 'the Enter' method, was used for the SPSS analysis. In this method, the user enters all independent variables (the indicators under the particular components) simultaneously into the model. Variables were evaluated by what they add to the prediction of the dependent variable, which is different from the predictability afforded by the other predictors in the model (Nach 2009).

In order to test the component level hypotheses in terms of whether there is a significant linear relationship between the individual components in the theoretical model and the dependent variables, the F-test was used. It involved testing whether the set of the independent variables (indicators) collectively predicts the dependent variable for that particular component. The 'R-squared' multiple correlation coefficients of determination were also reported and used to determine how much variance in the dependent variable can be accounted for by the set of the independent variables. The t-test was used to determine the significance of each of the indicators and beta coefficients were used to determine the magnitude of prediction for each indicator variable. For significant predictors, every one-unit increase in the predictor meant the dependent variable will increase or decrease the number of unstandardized beta coefficients (Statistics Solutions, 2013).

By examining a scatter plot for each of the 13 regression models (components), the assumptions of multiple regression linearity, homoscedasticity and multicollinearity were assessed. The absence of multicollinearity in all assumes that predictor variables are not closely related. Hence, the models are valid for analysis (Solutions 2013). 


\section{THE CAPABILITY AND SUPPORT}

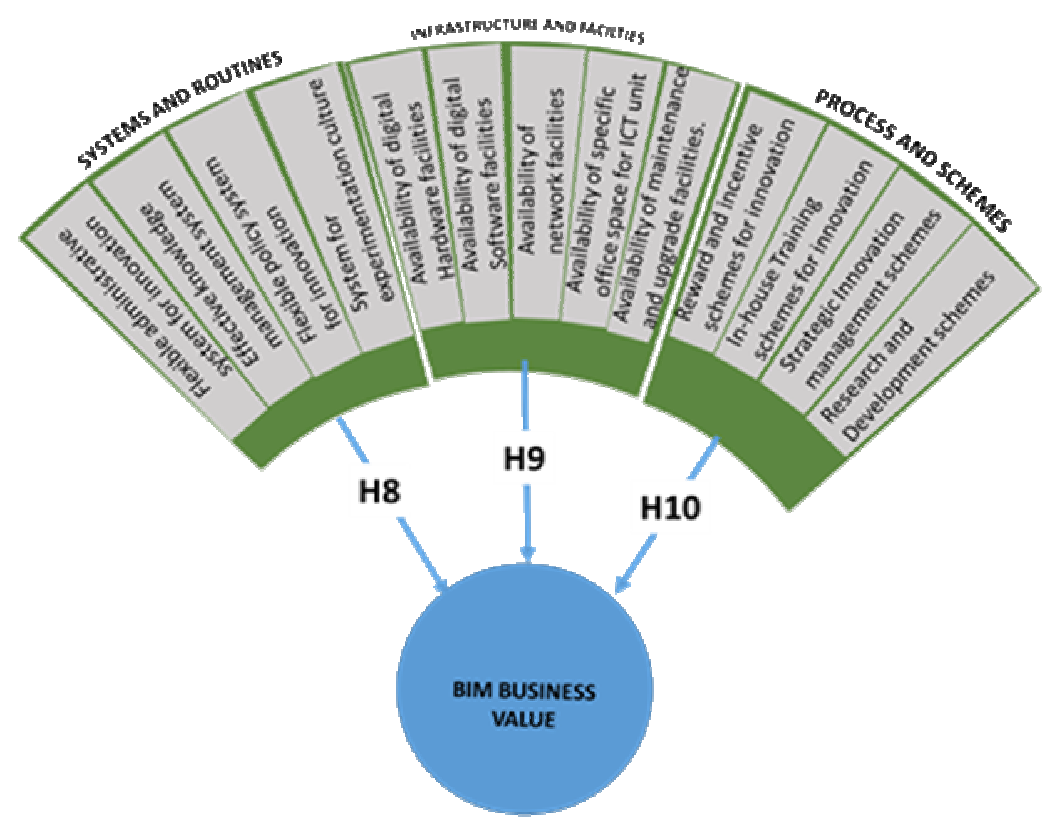

Figure 1. A model for SC components of BIM adoption in SME architectural firms

\section{Analysis}

This part deals with the SC analysis, and involves an analysis of the three SC components. The analysis will test each indicator as an independent variable against the dependent variable of BBVC. Hence, each component is treated as an independent model of regression with the indicators as predictors. Finally, there is a discussion on, and summary of, the findings at the end of the SC section.

\subsection{THE SYSTEM STRUCTURE COMPONENT}

This section presents the analysis of the relationship between the capability and support of the SME architectural firm's organisational system structure and BBVC.

THE REGRESSION ANALYSIS

A multiple regression analysis was conducted to investigate whether the capability and support for innovation within SME architectural firms, through their organisational system structure, have a significant correlation with BBVC. This involved analysing the effect of four indicators within the organisational system structure in predicting BBVC. The preliminary analysis shows that all assumptions are valid, and the potential variables of the indicators are accepted to carry out the multiple regression analysis.

3.1 Required Data Input

Table 1: Model summary for the organisational system structure component

\begin{tabular}{|l|l|l|l|l|}
\hline Model & $\mathrm{R}$ & R Square & Adjusted R Square & Std. Error of the Estimate \\
\hline 1 & $.679^{\mathrm{a}}$ & .461 & .451 & 1.05476 \\
\hline
\end{tabular}

a. Predictors: (Constant), System for experimentation culture, Flexible policy system for innovation, Flexible administrative system for innovation, Efficient knowledge management system

Table 1 shows the multiple linear regression model summary and overall fit statistics. The table shows that the adjusted $\mathrm{R}^{2}$ of the model is 0.451 with the $\mathrm{R}^{2}=0.461$, which means that the linear regression explains $46.1 \%$ of the variance in the data.

Table 2: Anova test for the organisational system structure component

\begin{tabular}{|ll|l|l|l|l|l|}
\hline Model & & Sum of Squares & df & Mean Square & F & Sig. \\
\hline 1 & Regression & 212.172 & 4 & 53.043 & 47.678 & $.000^{\mathrm{b}}$ \\
& Residual & 248.092 & 223 & 1.113 & & \\
Total & 460.263 & 227 & & & \\
\hline
\end{tabular}

a. Dependent Variable: BBVC

b. Predictors: (Constant), System for experimentation culture, Flexible policy system for innovation, Flexible administrative system for innovation, Effective knowledge management system 
Table 2 shows the linear regression's F-test, which has the null hypothesis, H80, that there is no linear relationship between the dependent variable and independent variable at the component level (in other words $\mathrm{R}^{2}=0$ ). The F-test shows an $\mathrm{F}$ value of 47.687 with a highly significant P-value; thus, the study can assume that the null hypothesis H80 is rejected. Hence, H81 is accepted. This means that, through their organisational system structure, there is a significant linear relationship at the components level between the capability and support of SME architectural firms and BBVC. However, to understand the direct effect, it is essential to conduct further analysis at the indicator level. Hence, the result of the analysis on the indicator level is presented in Table 3.

Table 3: Coefficient showing the linear regression estimates of all the indicators of the system structure components of BBVC

\begin{tabular}{|c|c|c|c|c|c|c|}
\hline \multirow{2}{*}{\multicolumn{2}{|c|}{ Model }} & \multicolumn{2}{|c|}{ Unstandardised Coefficients } & \multirow{2}{*}{$\begin{array}{l}\text { Standardised } \\
\text { Coefficients } \\
\text { Beta } \\
\end{array}$} & \multirow[b]{2}{*}{$\mathrm{t}$} & \multirow[b]{2}{*}{ Sig. } \\
\hline & & $\mathrm{B}$ & Std. Error & & & \\
\hline \multirow[t]{5}{*}{1} & (Constant) & 647 & .204 & & 3.174 & .002 \\
\hline & $\begin{array}{l}\text { Flexible administrative } \\
\text { system for innovation }\end{array}$ & -.043 & .083 & -.046 & -.516 & 607 \\
\hline & $\begin{array}{l}\text { Effecient knowledge } \\
\text { management system }\end{array}$ & 086 & .100 & .084 & .865 & .388 \\
\hline & $\begin{array}{l}\text { Flexible policy system for } \\
\text { innovation }\end{array}$ & 446 & .070 & .446 & 6.385 & .000 \\
\hline & $\begin{array}{l}\text { System for experimentation } \\
\text { culture }\end{array}$ & 279 & .083 & .271 & 3.382 & .001 \\
\hline
\end{tabular}

a. Dependent Variable: BBVC

Table 3 shows the multiple linear regression estimates of all the indicators, thus testing the four SubHypotheses, H8a-H8d, including the intercept and significance levels of the effect of each indicator on the IC and success level of BIM adoption. The unstandardised coefficients' Beta (B) value indicates the extent of the effects for each of the independent variable on the dependent variable BBVC. The table shows that firms that develop their capability and support as a result of flexible policy systems and an experimentation culture that supports innovation are likely to succeed in BBVC while the flexible administrative systems and knowledge management systems are not significant predictors of the success level of BIM adoption.

\subsection{THE ORGANISATIONAL INFRASTRUCTURES AND FACILITIES COMPONENT}

This section presents the analysis of the relationship between capability and support of SME architectural firms through their organisational facilities and infrastructure and BBVC.

THE REGRESSION ANALYSIS

A multiple regression analysis was conducted to investigate whether the capability and support of SME architectural firms' organisational infrastructure and facilities for innovation have a significant correlation with BBVC. This involved analysing the effect of five organisational infrastructure facility indicators in predicting the BBVC. Preliminary analysis shows that all assumptions are valid and the potential variables of the indicators are accepted to carry out the multiple regression analysis.

Table 4: Model summary for organisational infrastructure and facilities component

\begin{tabular}{|l|l|l|l|l|}
\hline Model & R & R Square & Adjusted R Square & Std. Error of the Estimate \\
\hline 1 & $.759^{\mathrm{a}}$ & .576 & .566 & .93811 \\
\hline
\end{tabular}

a. Predictors: (Constant), Availability of maintenance and upgrade facilities for technology, Availability of digital hardware facilities, Availability of network facilities, Availability of specific office space for ICT unit, Availability of digital software facilities

Table 4 shows the multiple linear regression model summary and overall fit statistics. The table shows that the adjusted $\mathrm{R}^{2}$ of the model is 0.566 with the $\mathrm{R}^{2}=0.576$, which means that the linear regression explains $57.6 \%$ of the variance in the data. 
Table 5: Anova test for the organisational infrastructure and facilities component

\begin{tabular}{|ll|l|l|l|l|l|}
\hline Model & & Sum of Squares & df & Mean Square & F & Sig. \\
\hline 1 & Regression & 264.891 & 5 & 52.978 & 60.199 & $.000^{\mathrm{b}}$ \\
& Residual & 195.372 & 222 & .880 & & \\
& Total & 460.263 & 227 & & & \\
\hline
\end{tabular}

a. Dependent Variable: BIM adoption level

b. Predictors: (Constant), Availability of maintenance and upgrade facilities for technology, Availability of digital hardware facilities, Availability of network facilities, Availability of specific office space for ICT units, Availability of digital software facilities

Table 5 shows the linear regression's F-test, which has the null hypothesis, H90, that there is no linear relationship between the dependent variable and independent variable at the component level (in other words $\mathrm{R}^{2}=0$ ). The F-test shows an $\mathrm{F}$ value of 60.199 with a highly significant $\mathrm{P}$-value; thus the study can assume that the null hypothesis, H90, is rejected. Hence, H91 is accepted which means there is a significant linear relationship between the capability and support of organisational infrastructure and facilities of SME architectural firms with BBVC at the components level. However, to understand the direct effect, it is essential to conduct further analysis at the indicator level. Hence, the result of the analysis on the indicator level is presented in Table 6.

Table 6: Coefficient showing the linear regression estimates of the indicators of the organisational infrastructure and facilities components of BBVC

\begin{tabular}{|c|c|c|c|c|c|}
\hline \multirow[b]{2}{*}{ Model } & \multicolumn{2}{|c|}{$\begin{array}{l}\text { Unstandardised } \\
\text { Coefficients }\end{array}$} & \multirow{2}{*}{\begin{tabular}{|l} 
Standardised \\
Coefficients \\
Beta
\end{tabular}} & \multirow[b]{2}{*}{$\mathrm{t}$} & \\
\hline & $\mathrm{B}$ & Std. Error & & & Sig. \\
\hline 1 (Constant) & .791 & .179 & & 4.405 & \\
\hline Availability of digital Hardware facilities & .261 & .093 & .280 & 2.793 & \\
\hline Availability of Digital Software facilities & .236 & .098 & .234 & 2.410 & .017 \\
\hline Availability of network facilities & .246 & .081 & .244 & 3.023 & 3.003 \\
\hline Availability of specific office space for ICT unit & .097 & .093 & .094 & 1.044 & .298 \\
\hline $\begin{array}{l}\text { Availability of maintenance and upgrade facilities } \\
\text { for technology. }\end{array}$ & 407 & .082 & .435 & 4.981 & \\
\hline
\end{tabular}

a. Dependent Variable: BIM adoption level

Table 6 shows the multiple linear regression estimates of all the indicators, thus testing the four subhypotheses, H9a-H9e, including the intercept and the significance levels of the effect of each indicator of the IC and the success level of BIM adoption. The unstandardised coefficients' Beta (B) value indicates the extent of the effects for each of the independent variable on the dependent variable BBVC. The table shows that to succeed in BBVC, firms develop their capability and support as a result of the availability of digital hardware facilities, digital software facilities, and network facilities and also maintain and upgrade such regularly to support technology. However, the availability of specific office space for ICT unit is not found to have any significant correlation with BBVC.

\subsection{THE ORGANISATIONAL PROCESS AND SCHEME COMPONENT}

This section presents the analysis of the relationship between the capability and support of the organisational process and schemes of SME architectural firms and BBVC.

THE REGRESSION ANALYSIS

A multiple regression analysis was conducted to investigate whether the capability and support of organisational process and schemes of SME architectural firms for innovation have a significant correlation with BBVC. This involved analysing the effect of four organisational process and scheme indicators in predicting BBVC. Preliminary analysis shows that all assumptions are valid and the potential variables of the indicators are accepted to carry out the multiple regression analysis.

Table 7: Model summary for the organisational process and scheme component

\begin{tabular}{|l|l|l|l|l|}
\hline Model & R & R Square & Adjusted R Square & Std. Error of the Estimate \\
\hline 1 & $.791^{\mathrm{a}}$ & .626 & .620 & .87817 \\
\hline
\end{tabular}

Predictors: (Constant), Research and development schemes, In-house training schemes for innovation, Reward and incentive schemes for innovation, Strategic innovation management schemes

Table 7 shows the multiple linear regression model summary and overall fit statistics. The table shows that the adjusted $\mathrm{R}^{2}$ of the model is 0.620 with the $\mathrm{R}^{2}=0.626$, which means that the linear regression explains $62.6 \%$ of the variance in the data. 
Table 8: Anova test for the organisational and process scheme component

\begin{tabular}{|ll|l|l|l|l|l|}
\hline Model & & Sum of Squares & df & Mean Square & F & Sig. \\
\hline 1 & Regression & 288.289 & 4 & 72.072 & 93.456 & $.000^{\mathrm{b}}$ \\
& Residual & 171.975 & 223 & .771 & & \\
& Total & 460.263 & 227 & & & \\
\hline
\end{tabular}

a. Dependent Variable: BIM adoption level

b. Predictors: (Constant), Research and development schemes, In-house training schemes for innovation, Reward and incentive schemes for innovation, Strategic innovation management schemes

Table 8 shows the linear regression's F-test, which has the null hypothesis, H100, that there is no linear relationship between the dependent variable and independent variable at the component level (in other words $\mathrm{R}^{2}=0$ ). The F-test shows an $\mathrm{F}$ value of 93.456 with a highly significant $\mathrm{P}$-value; thus, the study can assume that the null hypothesis H100 is rejected. Hence, H101 is accepted, which means there is a significant linear relationship between SME architectural firms' capability and support of organisational process and schemes, and BBVC at the components level. However, to determine the direct effect, it is essential to conduct further analysis at the indicator level. Hence, the result of the analysis on the level of the indicator is presented in the next table.

Table 9: Coefficient showing the linear regression estimates of all the indicators of the organisational and process scheme component on BBVC

\begin{tabular}{|c|c|c|c|c|c|}
\hline \multirow[b]{2}{*}{ Model } & \multicolumn{3}{|c|}{ Unstandardised Coefficients Standardised Coefficients } & \multirow{2}{*}{$\mathrm{t}$} & \multirow[b]{2}{*}{ Sig. } \\
\hline & $\mathrm{B}$ & Std. Error & Beta & & \\
\hline 1(Constant) & .165 & .174 & & .951 & .343 \\
\hline Reward and incentive schemes for innovation & .380 & .084 & .371 & 4.507 & 7.000 \\
\hline In-house training schemes for innovation & -.033 & .077 & -.037 & -.436 & .663 \\
\hline Strategic innovation management schemes & .351 & .089 & .331 & 3.951 & .000 \\
\hline Research and development schemes & .201 & .079 & .213 & 2.548 & .012 \\
\hline
\end{tabular}

a. Dependent Variable: BIM adoption level

Table 9 shows the multiple linear regression estimates of all the indicators, thus testing the four subhypotheses, H10a-H10d, including the intercept and significance levels on the effect of each IC indicator on the success of BIM adoption. The unstandardised coefficients' Beta (B) value indicates the extent of the effects for each of the independent variable on the dependent variable BBVC. The table shows that firms that develop their capability and support as a result of their rewards and incentives, strategic innovation management schemes, and research and development are likely to succeed in BBVC, while in-house training schemes were not found to be a significant predictor of BBVC.

\section{CONCLUSION}

The objective of this research was to analyse the influence of SC on BBVC in SME architectural firms. A multiple regression analysis was conducted between the independent variables, consisting of various indicators under the three SC components, and the dependent variable of BBVC. The analysis is a test of the hypotheses, one of which was validated by the results in this section.

The result indicated that all the three components of the SC that were identified in the literature review have a significant correlation with BBVC. However, some indicators were not found to be useful in predicting BBVC, which include: flexible administrative systems and knowledge management system structures. In comparison, the availability of specific office infrastructures for BIM and the availability of in-house training were found to be useful. Figure 2 shows the result of the analysis of the effect of the different indicators on the BBVC. Indicators in red are those rejected while those in ash are accepted. 


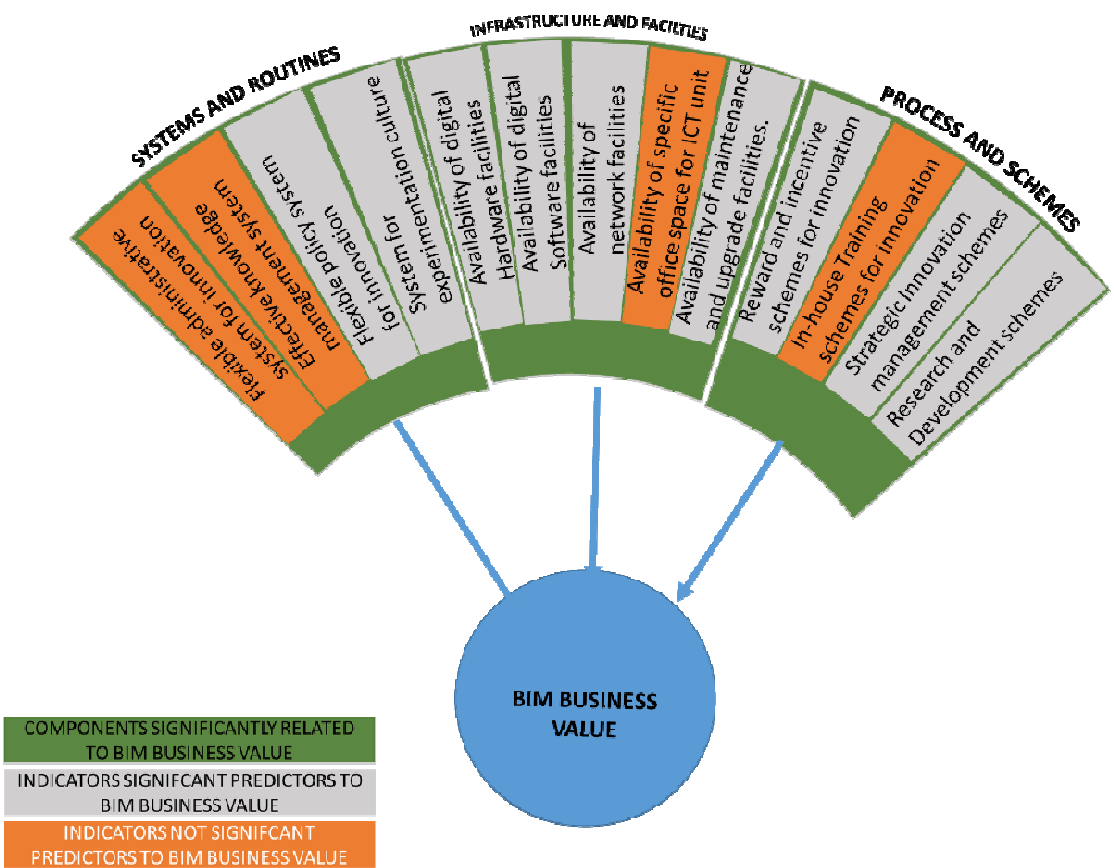

Figure 2: Evaluation for SC showing the critical components and indicators that predict BBV

The development of the SC of SME architectural firms in the AEC industry is essential for the business process of BIM adoption, and helps firms to evaluate their capacity for innovation. This development involved three critical components in terms of system structure, infrastructure and facilities, and process and scheme. The BIM adoption process involves restructuring the policy system of a firm and that should enable an experimentation culture. This is enabled by a fitting infrastructure and facilities for leveraging technology, which includes: software, hardware, networks and the regular maintenance and upgrade of such facilities. The process also involved the formalisation of incentives and rewards, strategic innovation management, and adequate research and development.

The rejection of a flexible administration system and effective knowledge management system under the system and routines of the firms may be attributed due to conservative nature of the architectural profession where the profession is more valued than any competitive advantage of innovation. This may also be consistent with the reason why the availability of specific office for ICT unit was also found to be rejected. However, in the case of in-house training is a peculiar case which is often regarded as an important organ of every professional organisation.

\section{References}

Aramburu, N., J. Sáenz \& C. Blanco. 2013. Structural capital, innovation capability, and company performance in technology-based colombian firms. In Proceedings of the International Conference on Intellectual Capital, Knowledge Management \& Organizational Learning, 20-29.

Aranda-Mena, G., J. Crawford, A. Chevez \& T. Froese (2009) Building information modelling demystified: does it make business sense to adopt BIM? International Journal of managing projects in business, 2, 419-434.

Arayici, Y., P. Coates, L. Koskela, M. Kagioglou, C. Usher \& K. O'reilly (2011) Technology adoption in the BIM implementation for lean architectural practice. Automation in Construction, 20, 189-195.

Barlish, K. \& K. Sullivan (2012) How to measure the benefits of BIM-A case study approach. Automation in construction, 24, 149-159.

Chen, J., Z. Zhu \& H. Yuan Xie (2004) Measuring intellectual capital: a new model and empirical study. Journal of Intellectual Capital, 5, 195-212.

Codinhoto, R., A. Kiviniemi, S. Kemmer \& C. G. da Rocha (2013) BIM-FM implementation: an exploratory investigation. International Journal of 3-D Information Modeling (IJ3DIM), 2, 1-15.

Construction, M. H. (2014) The Business Value of BIM For Construction in Major Global Markets: how contractors around the world are driving innovation with building information modeling. Smart MarketReport.

Curley, M. G. 2004. Managing Information Technology for Business Value: Practical Strategies for IT and Business Managers (IT Best Practices series). Intel Press.

Damanpour, F. \& S. Gopalakrishnan (2001) The dynamics of the adoption of product and process innovations in organizations. Journal of Management studies, 38, 45-65. 
Dorrego, P. F., R. V. Costa \& C. F.-J. Fernández (2013) Product innovation and relational capital: Evidence from Portugal. Electronic Journal of Knowledge Management, 11, 295-308.

Edvinsson, L. \& M. S. Malone (1997) Intellectual Capital: Realizing Your Company|'s True Value by Finding Its Hidden Brainpower.

Egbu, C. O. (2004) Managing knowledge and intellectual capital for improved organizational innovations in the construction industry: an examination of critical success factors. Engineering, Construction and Architectural Management, 11, 301-315.

Friedman, V. J., R. Lipshitz \& W. Overmeer (2001) Creating conditions for organizational learning. Handbook of organizational learning and knowledge, 757-774.

Ichijo, K. (2007) Enabling knowledge-based competence of a corporation. Knowledge creation and management: New challenges for managers, 83-96.

Kalla, H. K. (2005) Integrated internal communications: a multidisciplinary perspective. Corporate Communications: An International Journal, 10, 302-314.

Karchegani, M. R., S. Sofian \& S. M. Amin (2013) The relationship between intellectual capital and innovation: a review. International journal of business and management studies, 2, 561-581.

Kohli, R. \& V. Grover (2008) Business value of IT: An essay on expanding research directions to keep up with the times. Journal of the association for information systems, 9, 23.

Kori, S. i. \& A. Kiviniemi. 2015. Toward Adoption of BIM in the Nigerian AEC Industry; Context Framing, Data Collecting and Paradigm for Interpretation. 34-41. http://bimforum.org/wp-content/uploads /2015/05/BIMAS2015Proceedings.compressed.pdf

KTH 2015. An Organizational Perspective on the Business Value of BIM. KTH Royal Institute of Technology.

Lichtenthaler, U. \& E. Lichtenthaler (2009) A capability-based framework for open innovation: Complementing absorptive capacity. Journal of management studies, 46, 1315-1338.

Lu, S. L. \& M. Sexton. 2009. Innovation in Small Professional Practices in the Built Environment. Wiley.

McGraw-Hill (2009) The Business Value Of BIM. Getting Building Information Modeling to the Bottom Line. Bedford: McGraw Hill Construction.

Nach, E. J. 2009. Instructional use of research-based practices for students with autism spectrum disorder. ProQuest.

Namvar, M., M. Fathian, M. R. Gholamin \& P. Akhavan (2012) Exploring the Role of Human Capital on Firm's Structural Capital in Iranian E-Business Industry.

Newton, P., K. Hampson \& R. Drogemuller. 2009. Technology, Design and Process Innovation in the Built Environment. Taylor \& Francis.

Ngah, R. \& A. R. Ibrahim (2011) The Influence of Intellectual Capital on Knowledge Sharing: Small and Medium Enterprises' Perspective. Communications of the IBIMA.

Nonaka, I. \& H. Takeuchi (1996) The knowledge-creating company: How Japanese companies create the dynamics of innovation. Long Range Planning, 29, 592.

Nonaka, I. \& R. Toyama (2003) The knowledge-creating theory revisited: knowledge creation as a synthesizing process. Knowledge Management Research \& Practice, 1, 2-10.

Racheva, Z., M. Daneva \& K. Sikkel. 2009. Value creation by agile projects: Methodology or mystery? In International Conference on Product-Focused Software Process Improvement, 141-155. Springer.

Solutions, S. 2013. Data analysis plan: Moderation Analysis [WWW Document]. Retrieved.

Succar, B. (2009) Building information modelling maturity matrix. Handbook of Research on Building Information Modeling and Construction Informatics: Concepts and Technologies, IGI Global, 65-103.

Succar, B. \& M. Kassem (2015) Macro-BIM adoption: Conceptual structures. Automation in Construction, 57, 64-79.

Succar, B., W. Sher \& A. Williams (2012) Measuring BIM performance: Five metrics. Architectural Engineering and Design Management, 8, 120-142.

Vass, S. 2014. A proposed BIM business value model. In 30th Annual Association of Researchers in Construction Management Conference, ARCOM 2014; Portsmouth; United Kingdom, 633-642. 